\title{
Foucault: de Binswanger a Kant ${ }^{1}$
}

\author{
Foucault: from Binswanger to Kant
}

\author{
Monica Loyola Stival \\ monicastival@hotmail.com \\ (Universidade Federal de São Carlos, São Paulo, Brasil)
}

Resumo: Foucault interessa-se, nos anos 1950, pela obra de Binswanger. Ela Ihe parece contornar as aporias da psicologia. Contudo, no desenvolvimento dessa analítica da existência Foucault nota dificuldades que o levam a retomar Kant, por meio de uma leitura de sua Antropologia de um ponto de vista pragmático. Pretendo recompor os termos dessa mudança de perspectiva a fim de circunscrever questões decisivas para 0 estabelecimento da filosofia de Foucault. 0 ponto fundamental está no estatuto das condições de existência. Essas con dições escapam, por princípio, à existên: cia tomada como signo, pois não podem ser encontradas aquém da tripartição de uma filosofia transcendental.

Palavras-chave: Foucault; Kant; Binswanger; antropologia; condições de existência.
Abstract: In the 1950s, Foucault becomes interested in the work of Binswanger. It seems to him that it circumvents the aporias of psychology. However, in the development of this analytical of existence, Foucault realizes some difficulties that lead him to resume Kant, through a reading of his Anthropology from a pragmatic point of view. I intend to restore the terms of this shift in perspective in order to circumscribe decisive matters for establishing Foucault's philosophy. The key point is the status of the conditions of existence. These conditions are beyond, in principle, the existence taken as a sign, for they cannot be found unawarely of the tripartition of a transcendental philosophy.

Keywords: Foucault; Kant; Binswanger, anthropology; conditions of existence.

DOI: http://dx.doi.org/10.11606/issn.2318-9800.v19i2p131-148

1. Este artigo recupera parte de minha tese de doutorado, intitulada "Foucault entre a crítica e o nominalismo", defendida na Universidade de São Paulo em 2013. A pesquisa contou com financiamento do CNPq - Conselho Nacional de Desenvolvimento Científico e Tecnológico. 
Para situar o ponto de partida filosófico de Foucault, procuro indicar as linhas gerais do deslocamento que ele opera entre 1954 e 1961, marcado pelas introduções que escreve às obras de Binswanger e de Kant, respectivamente, Sonbo e existência e Antropologia de um ponto de vista pragmático. A transformação de perspectiva, de uma obra à outra, explicita as preocupações iniciais de Foucault, que o levarão em breve à formulação de sua "arqueologia". O tema deste artigo são essas preocupações iniciais, de modo que estou tratando exclusivamente da presença da obra de Binswanger e de Kant nesse momento inicial da pesquisa de Foucault.

Em 1954, o horizonte de Foucault é essencialmente fenomenológico e humanista. Esse espírito fenomenológico é compartilhado por grande parte dos estudantes da geração de Foucault, e tal hegemonia não poderia deixar de ser a origem de sua própria recusa. Assim, a "análise das significações imanentes ao vivido", das "significações implícitas da percepção e da história" suscita o problema das condições de aparecimento da significação, colocando o projeto fenomenológico em questão. Nas palavras de Foucault, tornou-se urgente compreender as "condições formais que podem fazer que a significação apareça" ${ }^{\prime \prime}$. Essas condições formais não poderiam ser destacadas de uma análise existencial. A constatação do sentido profundo dessa impossibilidade está estreitamente ligada à percepção, por Foucault, da necessidade de manter a tripartição crítica da filosofia transcendental de Kant. É esse o mote, parece-me, da transformação que ocorre entre 1954 e 1961 na pesquisa de Foucault, e fornece os elementos principais para justificar a formulação da arqueologia.

\section{I}

Foucault desenvolve sua arqueologia a partir da certeza de que as condições formais da significação devem ser vistas como históricas e deslocadas, portanto, do campo circular empírico-transcendental que as analíticas da finitude herdaram de Kant. A origem do que Foucault chama duplo empírico-transcendental parece estar, em parte, na dupla forma da representação do "eu", tal como formulada por Kant. Essa dupla forma se estabelece pela posição psicológica do "eu" em

2. Trata-se da "análise das condições formais da aparição do sentido". FOUCAULT, M. Qui êtes vous, professeur Foucault?, 50. In: Dits et écrits, I. Paris: Gallimard, 2001, p. 630. Doravante DE. 
relação à posição lógica da representação deste mesmo "eu". Segundo Kant, "na Psicologia nós nos examinamos segundo nossas representações do sentido interno; mas na Lógica, segundo o que a consciência intelectual nos oferece. Aqui, o Eu $(\mathrm{Je})$ parece ser duplo (o que seria contraditório): 1) O Eu como sujeito do pensamento (na Lógica), que significa a apercepção pura (o Eu puramente reflexionante), e do qual não se pode dizer absolutamente nada, exceto que ele é uma representação absolutamente simples. 2) O Eu como objeto da percepção, logo, do sentido interno, que contém uma multiplicidade de determinações, tornando possível uma experiência interior ${ }^{13}$.

Todavia, Foucault entende, em 1954, que "assim como a antropologia recusa toda tentativa de repartição entre filosofia e psicologia, do mesmo modo a análise existencial de Binswanger evita uma distinção a priori entre ontologia e antropologia" ${ }^{\prime 4}$. Pode-se ler nesta passagem de Foucault um ponto importante da distinção radical entre a antropologia de Binswanger e a de Kant. O que faz com que a análise de Binswanger não possa, contrariamente à formulação kantiana, partir de uma separação a priori entre ontologia e antropologia é que, em uma reflexão antropológica à maneira fenomenológica, a psicologia não se distingue (ao menos a priori) da posição lógica do "eu". Vejamos essa distinção em Kant, particularmente na sua Antropologia, para marcar a distância de sua formulação em relação à proposta de Binswanger.

A consciência de si mesmo ${ }^{5}$ é tema do primeiro parágrafo da Antropologia de um ponto de vista pragmático de Kant. O foco é a possibilidade de representação do "eu" lógico, o qual acompanha potencialmente as representações do homem, permitindo a formulação do "eu" psicológico. A passagem em questão é aquela que permite a criança passar do "sentir-se" ao "pensar-se" - como diz Kant, "antes, ela não fazia outra coisa que se sentir; agora ela se pensa"6. Tal é a condição de possibilidade da expressão em primeira pessoa "eu", entendida então como formulação da consciência empírica da unidade já dada - como possibilidade permanente de representação - em seu sentido lógico.

3. Kant, I. Antbropologie du point de vue pragmatique. Traduit et prefacé par Michel Foucault. Paris: VRIN, 2002, p. 32, nota 1. Doravante "Anthropologie".

4. DE I, Introduction, 1, p. 95.

5. Parágrafo 1: Vom Bewußtsein seiner selbst; que Foucault traduz por "De la connaissance de soi".

6. Antbropologie, p. 24. 
A expressão em primeira pessoa é contemporânea, assim, ao começo da experiência. Nas palavras de Kant: "A experiência é então essa representação pela qual um objeto dos sentidos é dado (um objeto da percepção, isto é, da intuição empírica), mas a experiência ou o conhecimento empírico é essa representação pela qual ele é ao mesmo tempo pensado enquanto tal" ${ }^{\prime \prime 7}$. O campo da experiência abre-se à criança como apreensão do "pensar-se", ou seja, com a linguagem. Antes disso, "não era absolutamente o tempo das experiências, mas aquele das percepções dispersas, não ainda reunidas sob o conceito do objeto $^{\prime \prime}$. O uso empírico da linguagem é índice da reunião do disperso sob o conceito do objeto, de modo que se pode falar, talvez, que aqui Kant apresenta uma gênese empírica da organização, pelo entendimento, da experiência sensível. Isso porque, na sua Antropologia, o uso do entendimento marca a gênese da consciência de si mesmo, que, ela própria, é o começo da experiência concreta.

Já para Binswanger o sujeito ("eu"), no sonho, não é "descrito como uma das significações possíveis de um dos personagens, mas como o fundamento de todas as significações eventuais do sonho e, nessa medida, ele não é a reedição de uma forma anterior ou de uma etapa arcaica da personalidade, ele se manifesta como o devir e a totalidade da própria existência" ${ }^{\prime \prime}$. Esse sujeito é ele próprio a significação da transcendência expressa no sonho. A unidade de consciência que define experiência para Kant, marcada pela primeira pessoa do singular "eu" da linguagem, aparece em Binswanger conforme a experiência onírica: "no sonho, tudo diz 'eu' (je) (...). Sonhar não é outra maneira de fazer a experiência de outro mundo, é, para o sujeito que sonha, a maneira radical de fazer a experiência de seu mundo, e se essa maneira é a tal ponto radical, é que a existência não se anuncia no sonho como sendo o mundo" ${ }^{\prime \prime}$.

O campo da experiência, de um modo ou de outro delimitado pela linguagem, parece alargar-se, em Binswanger, ultrapassando o limite da Crítica; não em direção ao suprassensível, mas em direção à natureza das categorias do entendimento. É o impulso de esgotar na reflexão ontológica a exploração do sentido da experiência (no caso,

7. Idem, variantes, p. 279.

8. Idem, p. 24.

9. DE I, Introduction, 1, p. 126.

10. Idem, p. 128. 
do sentido Ser, pois se trata de uma investigação inteiramente devedora da fenomenologia heideggeriana), sem considerar o motivo que fazia a ontologia ser, na Crítica, preparativo à metafísica ${ }^{11}$. Na contramão desta leitura, que Gérard Lebrun faria vir a público pouco mais de uma década depois, a perspectiva de cunho heideggeriano traz para a análise da existência o mundo transcendente. $\mathrm{O}$ "mundo transcendente" fornece a lógica de significação, de sentido, para o que o homem está de algum modo aberto. É por meio da instância do sonho que Binswanger localiza a transcendência na imanência, anulando a postulação de uma esfera transcendental, fazendo sua antropologia desdobrar-se em ontologia: em um dado momento da análise, "abandona-se o nível antropológico da reflexão que analisa o homem enquanto homem e no interior de seu mundo humano, para ter acesso a uma reflexão ontológica que concerne ao modo de ser da existência como presença no mundo"12. É esta possibilidade que animava Foucault, ainda nos anos 1950.

Em 1954, parecia a Foucault que, "de fato, não pode tratar-se de remeter as estruturas de expressão ao determinismo das motivações inconscientes, mas de poder restituí-las ao longo dessa linha segundo a qual a liberdade humana se move ${ }^{113}$. Ora, esse movimento, que não se refere a uma gênese, mas à realização ou alienação de certa liberdade, permite que o sonho seja analisado por Binswanger, segundo Foucault, como narrativa poética. "Não designaria ele [o sonho], ao mesmo tempo, o conteúdo de um mundo transcendente, e o movimento originário da liberdade?"14. Por meio de um ou outro modo de expressão narrativa seria possível então descrever a dimensão que dá significado à experiência.

São três as direções, os modos de expressão: épica, lírica e trágica. Trata-se de maneiras distintas de narrar a experiência, de analisar a existência - não se trata, pois, de metáforas para descrevê-la, mas de estrutura narrativa. Elas correspondem à temporalidade épica, lírica e trágica. A expressão épica diz respeito ao movimento espacial que se define na direção que vai do espaço próximo ao longínquo, reportan-

11. Cf. LEBRUN, G. Kant e o fim da metafísica. Tradução de Carlos Alberto Ribeiro de Moura. São Paulo: Martins Fontes, 1993, p. 56.

12. DE I, Introduction, 1, p. 137.

13. Idem, p. 133.

14. Idem, p.121. 
do-se ao que Schelling denomina "Odisseia da existência", e aparece como "estrutura fundamental do ato expressivo". A expressão lírica diz respeito à alternância sazonal de luz e de obscuridade, que circunscreve um exílio próprio e sem retorno. Por último, a expressão trágica é o eixo vertical da existência, oscilando em ascensão e queda, motivo pelo qual "a tragédia não necessita ser ouvida no tempo e no espaço, ela não precisa nem de terras estranhas, nem mesmo do apaziguamento das noites, se é verdade que ela se dá a tarefa de manifestar a transcendência vertical do destino"15.

Para Foucault, isso significa que as estruturas próprias a tais expressões têm fundamento antropológico, fundamento que rege os atos expressivos da existência. Quer dizer, as estruturas de análise da existência estão fundadas na dimensão antropológica, e não em categorias que a transcendam e organizem "de fora" a experiência. Ora, mas "como se constituem essas direções essenciais da existência, que formam como que a estrutura antropológica de toda sua história?"16. Binswanger teria insistido, segundo Foucault, apenas sobre a expressão de ascensão e queda, vertical, trágica, já que é a mais fundamental, originária. $\mathrm{O}$ privilégio desta dimensão está na temporalidade que a concerne e que a revela como expressão propriamente universal ou universalizante. A dimensão trágica é movimento em direção à totalidade.

Sendo movimento da liberdade em direção à totalidade, é também o movimento de aniquilação, assim como a noite é a aniquilação de cada dia. No que tange à temporalidade, a expressão épica é aquela de uma horizontalidade temporal pautada por uma cronologia espacial, ou seja, na qual o tempo "se esgota na marcha" e só se renova "na forma da repetição, do retorno e da nova partida"17, tal como o tempo nostálgico e circular da epopeia. O tempo da expressão lírica é o tempo da oscilação, "um tempo sazonal, no qual a ausência é sempre promessa de retorno e a morte, fiança de ressurreição ${ }^{\prime \prime 18}$. Estas duas são formas inautênticas da temporalidade, o que significa que não alcançam a esfera fundamental: a transcendência de que o sonho é signo é designada pelo eixo vertical, pela dimensão trágica da experiência. "É preciso, portanto, conceder um privilégio absoluto - sobre

\footnotetext{
15. Idem, p. 134 .

16. Idem, ibidem

17. Idem, p. 135.

18. Idem, ibidem.
} 
todas as dimensões significativas da existência - à dimensão da ascensão e da queda: é nela e somente nela que podem decifrar-se a temporalidade, a autenticidade e a historicidade da existência" ${ }^{19}$.

A linha de movimento da liberdade humana pode ser pensada também no movimento da imaginação (Spielen) da exposição antropológica de Kant. Entretanto, o modo vertical da expressão não poderia ter qualquer valor para fazer, na antropologia kantiana, que a transcendência fosse significativa a partir de um signo da própria existência concreta. Ou seja, não é uma relação de signo e significado que funciona como "elo" entre o eu psicológico e o eu lógico. Do texto de 1954 à tese complementar de 1961, há uma importante alteração no modo como Foucault compreende a relação entre o empírico e o transcendental, já que perguntar pelas condições formais do aparecimento do sentido será perguntar por algo que escapa à estrutura de significação apresentada na Introdução à obra de Binswanger como a dimensão trágica da experiência. Trata-se agora de buscar as condições de existência do significado fora de uma totalidade metafisicamente postulada.

Contudo, não é reeditando a filosofia transcendental kantiana que Foucault quer trazer à luz tais condições, já que elas devem ser de existência e não de possibilidades, remetidas, então, como forma, diretamente à história concreta. De todo modo, Foucault entende que a procura por essas condições formais do significado - e, no limite, de toda prática discursiva - não pode prescindir da distinção kantiana entre a dimensão empírica e a transcendental.

\section{II}

Mas qual a insuficiência da perspectiva fenomenológica que Binswanger oferece? Trata-se do tratamento de certos modos de existência, o sonho, particularmente, como signo da significação dessa mesma existência. Vejamos, percorrendo novamente o caminho da Antropologia kantiana até a análise existencial de Binswanger, tal como Foucault a apresenta.

Kant distingue antropologia pragmática e antropologia fisiológica, entendendo o que o homem faz de si conforme sua livre atividade como tema da antropologia pragmática e aquilo que a natureza faz do homem como problema próprio da antropologia fisiológica.

19. Idem, p. 137. 
Para Kant, o sonho é o lugar da não discursividade, pois, embora não haja supressão do tempo, ele escapa à realização em vista da totalidade, da Razão. "No sono (quando se está com boa saúde), ser o joguete involuntário de suas imagens é sonhar ${ }^{\prime \prime 20}$. Ser o joguete involuntário das imagens significa que a imaginação, neste caso, não regula absolutamente o jogo das imagens; elas não estão, portanto, totalmente conforme as formas a priori do espaço, do tempo e, sobretudo, dos conceitos puros do entendimento. Não há continuidade temporal entre noites de sonhos. Nos sonhos há invenção por parte da imaginação, mas invenção involuntária, a ponto de estar quase no campo da antropologia fisiológica, já que a imaginação atua livremente segundo a forma da fantasia (fantasme). Nesse sentido, "nós jogamos frequentemente e de bom grado com a imaginação; mas a imaginação (enquanto fantasmagoria) joga frequentemente conosco e às vezes bem a contratempo"21.

Note-se que 1) o sonho é, para Binswanger, signo da transcendência, ele é signo de certa significação [1954]; 2) para Kant o sonho não participa propriamente do campo dos signos, mas apenas aquilo que está no tempo - aquilo que é sentido interno, signo de uma passividade originária, pelo menos na leitura foucaultiana da obra [1961]. "A apercepção que a Crítica remetia à simplicidade do Eu penso é aproximada agora da atividade originária do sujeito, enquanto o sentido interno, que a Crítica analisava segundo a forma a priori do tempo, é aqui dado na diversidade primitiva de um 'Gedankenspiel', que se joga fora do controle do sujeito, e que faz do sentido interno mais o signo de uma passividade primeira do que uma atividade constitutiva"22.

É nesse campo da passividade originária que aparece certa liberdade antropológica, anterior à atividade constitutiva do entendimento (para o "eu", o pensar-se). "Longe de que o domínio da Antropologia seja aquele do mecanismo da natureza e das determinações extrínsecas (ela seria então uma 'psicologia'), ele é inteiramente habitado pela presença surda, frouxa e frequentemente desviada, de uma liberdade que se exerce no campo da passividade originária" ${ }^{123}$.

20. Antbropologie, p. 73.

21. Idem, p. 82.

22. FOUCAULT, M. Introduction à l'Antbropologie de Kant. Thèse complémentaire pour le doctorat ès Lettres. Paris: VRIN, 2008, p. 22. Doravante IAK.

23. Idem, p. 24. 
Ora, a distinção entre psicologia e lógica (sentido interno é signo da apercepção, eu empírico é signo do eu lógico) reforça a ideia de que a Antropologia kantiana só se constitui na referência necessária ao "a priori" lógico, à Crítica e ao transcendental, que é outra coisa que a significação "liberdade" da qual o sentido interno é signo. $\mathrm{O}$ transcendental é pressuposto lógico da análise antropológica (uma lei lógica pressupõe a lei transcendental), contrariamente à transcendência que fundamenta a análise antropológica de Binswanger. Neste caso, a transcendência habita integralmente a existência concreta e não remete, portanto, a uma esfera transcendental (esgota-se como ontologia).

Foucault assegura, em 1954, que Binswanger "entendeu que uma antropologia desse estilo não pode fazer valer seus direitos senão mostrando como pode se articular uma análise do ser-homem com uma analítica da existência: problema de fundamento, que deve definir, na segunda, as condições da primeira, problema de justificação que deve colocar o valor das dimensões próprias e a significação autóctone da antropologia"24. Nesse sentido, a compreensão de que não se pode estabelecer o fundamento da análise do homem na analítica da existência torna-se inescapável, forçando a passagem da perspectiva fenomenológica de Binswanger ao horizonte kantiano. Afinal, as condições formais não podem ser identificadas como signos concretos. Para Foucault, a teoria da significação da fenomenologia mostra-se insuficiente porque parte da finitude positiva para encontrar suas condições de existência: o homem é dado primeiro e privilegiado para fundar o campo empírico. Para Kant, a separação a priori entre ontologia e antropologia pretendia justamente permitir um fundamento (estabelecer as condições) da análise do homem sem que fosse preciso - e mesmo possível - se fiar na análise da existência, pois esta última ignora que a existência fenomênica deve toda sua validade objetiva e possibilidade ao transcendental. Ao invés de partir do homem e reenviá-lo sempre a um campo transcendental que se abre a partir dele para fundá-lo, na circularidade duvidosa criticada por Foucault, a filosofia transcendental parte exatamente das condições transcendentais e, por conseguinte, lógicas da experiência, a fim de encontrar o ponto de vista pragmático como o movimento temporal concreto em que

24. DE I, Introduction, 1, p. 94. 
certa "liberdade pragmática" se desenrola sem, contudo, deixar de orientar-se pelo sistema da Razão.

É verdade que o próprio modo de exposição da antropologia pragmática de Kant não alcança a dimensão trágica da experiência, que seria a passagem vertical da experiência concreta a seu fundamento transcendental. Seria aceder à filosofia transcendental a partir da antropologia. Eis o que impede de partida uma analítica da finitude. E se não se trata, para Foucault, de colocar-se aquém da pergunta pelas condições da experiência possível, então a trama Crítica precisa oferecer uma saída distinta daquela em que se enredou a fenomenologia. Passo, com isso, a considerar o que a filosofia kantiana oferece como estrutura formal para pensar a significação da existência, pelo menos segundo Foucault, particularmente na Introdução de 1961. Trata-se de uma alternativa ao modelo de significação da análise existencial de Binswanger.

\section{III}

É na articulação entre as noções de a priori, originário e fundamental que, para Foucault, em 1961, toda filosofia moderna se encontra amarrada. "Desde Kant, implicitamente, o projeto de toda filosofia será superar essa divisão essencial, até que se torne clara a impossibilidade de um tal ultrapassamento fora de uma reflexão que a repete, e que repetindo-a, funda a divisão" 25 .

Vimos que o homem da antropologia é aquele que fala, e cuja experiência inicia precisamente na aquisição e articulação da língua, na possibilidade de comunicação, no final da primeira infância (etimologicamente, "não-fala"; como Unmündigkeit: "não-boca", sem fala; ou Bárbaros: não-língua) ${ }^{26}$. "É na troca da linguagem que, de uma só vez, ele alcança e realiza ele próprio o universal concreto. Sua resi-

25. IAK, p. 67.

26. Primo Levi relata o sonho que tem repetidamente - e que se repetia para muitos no campo de concentração -, no qual sua narração não é ouvida pelos familiares: "por que o sofrimento de cada dia se traduz, constantemente, em nossos sonhos, na cena sempre repetida da narração que os outros não escutam?" (Primo Levi, É isto um bomem? Tradução de Luigi Del Re. Rio de Janeiro: Rocco, 1988, p. 60). Aparece aí uma ligação estrita entre a ideia de inexistir como homem (sujeito) e a impossibilidade de comunicação. 
dência no mundo é originariamente estadia na linguagem ${ }^{1127}$. Se a linguagem é o que traz à baila as regras universais de composição, é porque corresponde à instância que propriamente "liga" Deus, homem e mundo; e como essa ligação é realizada pelo homem que fala, ele cumpre o papel de verbo, cópula. Este é o modelo de significação como o de Binswanger, também se constrói como estrutura narrativa - que Foucault procura absorver em sua pesquisa, recuando em relação ao modelo fenomenológico anterior.

Notemos que, não por acaso, Kant distingue consciência discursiva e consciência intuitiva. "A experiência é um conhecimento empírico, mas o conhecimento (visto que ele repousa em juízos) requer a reflexão (reflexio), por conseguinte, a consciência da atividade que compõe a multiplicidade da representação segundo a regra de sua unidade, isto é, o conceito e o pensamento em geral (diferente da intuição): nessas condições, a consciência será dividida em consciência discursiva (que deve preceder a título de consciência lógica, visto que ela dá a regra) e consciência intuitiva: a primeira (a pura apercepção da atividade do espírito) é simples" ${ }^{\prime \prime 2}$. Significa que a verdade, na dimensão antropológica, é constituída pela linguagem, e este é um ponto chave para Foucault. "A verdade que a Antropologia traz à tona não é então uma verdade anterior à linguagem e que ela seria encarregada de transmitir" ${ }^{\prime \prime 2}$. Não há conteúdo latente ou verdade antepredicativa, mas constituição linguística de toda verdade antropológica.

A unidade da tripartição é pensada por Foucault a partir da unidade linguística de uma proposição: "a trilogia Subjekt, Praedikat, Copula define a figura da relação entre Deus, o mundo e o homem"30. Justamente a noção de cópula, a função formal de "ligação" para formulação de um juízo, é criticada por Husserl na sexta Investigação Lógica - confessadamente, ponto decisivo para o pensamento heideggeriano ${ }^{31}$.

27. IAK, p. 64-65.

28. Antbropologie, p. 41.

29. IAK, p. 65.

30. Idem, p. 49.

31. Nas palavras de Heidegger: "a distinção que Husserl aí [na sexta Investigação Lógica] constrói entre intuição sensível e intuição categorial revelou-me seu alcance para a determinação do 'significado múltiplo do ente'"' (HEIDEGGER, M. Meu caminho para a fenomenologia. Coleção Os pensadores. São Paulo: Abril Cultural, 1979, p. 299). 
Na perspectiva husserliana, a cópula, que supõe uma exterioridade entre os termos (sujeito e predicado), deve ser substituída pela ideia de "intuição categorial", para que se dissolva a distância, que depende de categorias a priori, entre a "ontologia" e a "teologia" (na tripartição, predicado e sujeito). Todavia, a solução da "intuição categorial" interpretada por Heidegger como certa transcendência própria ao Dasein, entendido por Husserl como homem, faria da crítica de Husserl a Kant um caminho para o antropologismo (Heidegger ontologizaria aquela transcendência ao colocar a questão do Ser e, com ela, a interrogação sobre o homem). É assim que o próprio Husserl interpretou a solução heideggeriana, e num primeiro momento, em 1954, tal interpretação é similar à de Foucault.

Para Husserl, e provavelmente também para Kant, o problema da saída ontológica seria fazer da esfera do suprassensível um grau imanente ao Ser (sensível). Com isso, Heidegger acabaria por dissolver a esfera a priori que impede reduzir o mundo a uma espécie de totalidade plenamente acessível. O projeto transcendental evita essa dissolução. Para Foucault, o problema é driblar a saída via "intuição categorial" que, para Heidegger, abre espaço a uma ontologia fundamental. Esta via fenomenológica mostra-se equivocada ao pressupor o "homem" (Dasein, esta abertura para o Ser), motivo que faz Foucault passar do projeto de uma analítica existencial à maneira de Binswanger (1954) a uma crítica severa de todo "antropologismo". Este passo, que afasta Foucault da fenomenologia, está ligado então a uma releitura de Kant.

Foucault procura ressaltar em 1961 que a tripartição ou "divisão essencial" é o cerne do sistema kantiano por mostrar a relação entre Crítica, Antropologia e Filosofia transcendental conforme o quadro abaixo:

Crítica apriori Quellen (fonte) Deus Subjekt Antropologia originário Umfang (domínio) mundo Praedikat Filosofia transcendental fundamental Grezen (finitude) bomem Copula

No século XX, segundo Foucault, a Antropologia é deslocada para o lugar da $\mathrm{Crítica}^{32}$. Esse deslocamento é, para ele, um esqueci-

32. Esse deslocamento parece responsável pelo projeto de Les mots et les choses, já em 1954: “Uma obra posterior se esforçará por situar a análise existencial no 
mento da Crítica kantiana, origem do "sono antropológico" que se instaura como consequência da confusão entre cada esfera. Assim, se há uma espécie de elogio de Foucault à perspectiva pragmática da antropologia kantiana, ele se concentra na possibilidade de pensar o homem fora da estrutura de alienação em que a filosofia contemporânea reiteradamente o situa. "Assim, no elemento regrado da linguagem, a articulação das liberdades e a possibilidade, para os indivíduos, de formar um todo, podem se organizar sem a intervenção de uma força ou de uma autoridade, sem renúncia nem alienação $0^{\prime \prime 33}$. Trata-se mais de linguagem que de psicologia, o que parece ser ganho significativo da antropologia pragmática. Com efeito, o essencial para Foucault, no texto de 1961, é que "o problema da finitude passou de uma interrogação sobre o limite e a transgressão a uma interrogação sobre o retorno a $\mathrm{si}_{i}$ de uma problemática da verdade a uma problemática do mesmo e do outro" ${ }^{134}$.

Para concluir, e assinalar assim a questão da significação como aquela que faz Foucault passar de uma perspectiva fenomenológica, em 1954, a certa retomada do "formalismo" kantiano, em 1961, vale passar pela caracterização do homem nesta Antropologia.

\section{IV}

Segundo Kant, "como somente em sociedade e a rigor naquela que permite a máxima liberdade e, consequentemente, um antagonismo geral de seus membros e, portanto, a mais precisa determinação e resguardo dos limites desta liberdade - de modo a poder coexistir com a liberdade dos outros; como somente nela o mais alto propósito da natureza (...) pode ser alcançado pela humanidade (...) [então] uma constituição civil perfeitamente justa deve ser a mais elevada tarefa da natureza para a espécie humana" ${ }^{113}$. A concorrência engendrada em função da desigualdade entre os homens (antagonismo) tem em Kant

desenvolvimento da reflexão contemporânea sobre o homem ; nós tentaremos mostrar nessa obra, seguindo a inflexão da fenomenologia em direção à antropologia, quais fundamentos foram propostos à reflexão concreta sobre o homem" (FOUCAULT, M. DE I, Introduction, 1, p. 93).

33. IAK, p. 64.

34. Idem, p. 77-78.

35. KANT, I. Ideia de uma bistória universal de um ponto de vista cosmopolita, p. 10. 
a finalidade do equilíbrio. Por oposição ao egoísmo, a maneira pluralista de pensar é sintoma da liberdade propriamente dita, a liberdade moral. Parece haver então dois modos de liberdade em Kant. O primeiro é designado por ele como "liberdade selvagem"136, o segundo, como "liberdade moral". Vejamos de que modo o egoísmo e a liberdade selvagem parecem coincidir.

Kant procura mostrar, em sua Antropologia, que há três formas do egoísmo, que "progride irresistivelmente", conforme o entendimento, o gosto ou o interesse prático (três Criticas). Trata-se do egoísmo lógico, do egoísmo estético e do egoísmo prático.

O egoísmo lógico é aquele que não considera a importância do juízo de outrem para assegurar a verdade de seu juízo, cuja necessidade, entretanto, é reconhecida por aqueles que defendem a liberdade de imprensa: "se essa liberdade nos é recusada, tiram-nos ao mesmo tempo um meio importante de experimentar a exatidão de nossos próprios juízos, e nós estamos à mercê do erro"37. O "outro", ou o juízo de outrem, é aqui o limite da liberdade individual, e garante o bom uso público da razão. Contradizer a opinião geral é a audácia própria daqueles que têm o gosto do paradoxo, já que este paradoxo estaria na afirmação de sua liberdade de pensamento independentemente de algum critério exterior que limitasse o juízo. Trata-se então do perigo da excentricidade lógica: "quer-se não limitar os outros, mas passar por um homem de exceção; de fato, não se manifesta assim senão sua singularidade ${ }^{\prime \prime 38}$.

É um critério externo de limitação da liberdade que está em pauta também para o egoísta estético, que desdenha do juízo alheio: "ele se furta a todo aperfeiçoamento, isolando-se em seu juízo, aplaudindo a si próprio e buscando apenas em si o critério da beleza artística"39. Buscar fora de si o critério da beleza artística está ligado, para Kant, à ideia de aperfeiçoamento, logo, balizando o juízo por um critério o mais universal possível está-se julgando adequadamente, pois se trata do progresso da espécie (gênero humano), não do indivíduo.

\footnotetext{
36. Idem, p. 10-11.

37. Anthropologie, p. 25.

38. Idem, p. 26.

39. Idem, ibidem.
} 
O conflito entre a liberdade selvagem e algo que aparece como natureza (já que se trata de uma exterioridade que afeta o homem, limita e redireciona sua liberdade de ação constitutiva) aparece novamente para o egoísta moral: "esse egoísmo conduz a não ter nenhum critério para o exato conceito do dever, enquanto ele deve ser um princípio universalmente válido" ${ }^{40}$. O homem tem necessidade de um senhor, quando está entre outros de sua espécie, "pois ele certamente abusa de sua liberdade relativamente a seus semelhantes; e, se ele, como criatura racional, deseja uma lei que limite a liberdade de todos, sua inclinação animal egoísta o conduz a excetuar-se onde possa" ${ }^{\prime \prime 1}$. Esse desejo de uma lei será assim o resultado do reconhecimento da necessidade de uma medida universal, a necessidade de uma autoridade que sancione a diferença legítima entre os homens.

Parece haver, assim, uma espécie de abstração (ou alienação...) capaz de colocar o valor e a finalidade moral, prática e judicativa, naquilo que é externo ao sujeito. Por isso Foucault entende nascer com Kant a possibilidade da estrutura de alienação comum no pós-kantismo. Não há finalidade em si para o indivíduo; a finalidade está sempre ligada ao universal, à espécie (progresso). Por isso a necessidade da finalidade (da Razão) não é uma questão antropológica. Segundo Kant, para saber "se, como ser pensante, eu estou autorizado a aceitar fora da minha existência a existência de um todo de outros seres formando comigo uma comunidade (chamada o mundo), isso seria então uma questão não antropológica, mas puramente metafísica"42. A questão metafísica da Crítica pode ser entendida como a questão de saber sobre a necessidade e alcance daquela abstração ou alienação. Afinal, a capacidade de abstração é prova de "uma liberdade da faculdade de pensar e uma autonomia do espírito que permitem ter sob seu controle o estado de suas representações" ${ }^{\prime \prime 3}$.

Para pensar a necessidade da alienação, retome-se a leitura de Foucault quanto à esfera em que se situa a Antropologia. Segundo Foucault, o debate de Kant com Beck permite estabelecer "o espaço no qual uma Antropologia, em geral, era possível: região na qual a observação de si não acede nem a um sujeito em si, nem ao Eu $(J e)$

40. Idem, p. 27.

41. KANT, I. Ideia de uma bistória universal de um ponto de vista cosmopolita, p. 11.

42. Antbropologie, p. 27.

43. Idem, p. 28-29. 
puro da síntese, mas a um eu (moi) que é objeto, e presente somente em sua única verdade fenomenal"44. Contudo, o eu como objeto é, conforme a definição kantiana, objeto da Psicologia, e a dimensão da Antropologia só pode ser pensada a partir da Lógica e, em última instância, a partir da Filosofia Transcendental. Que a região da Antropologia seja esta, que não leve a um sujeito em si ou ao "eu" puro da síntese, não quer dizer que a delimitação da dimensão de questões que lhe concernem possa ser traçada "de dentro" do campo fenomênico, a julgar pela referência de Kant a esta questão como metafísica.

Por isso, o limite do estilo fenomenológico já está presente quando Foucault nota, em 1954, que "uma análise nesse sentido fenomenológico não pode bastar-se a si própria. Ela deve concluir-se e fundar-se. Concluir-se, por uma elucidação do ato expressivo que dá uma figura concreta a essas dimensões originárias da existência; fundar-se, através de uma elucidação desse movimento no qual se constituem as direções de sua trajetória"45. É essa necessidade que vivifica a interrogação sobre a relação entre Antropologia e Crítica, uma vez que ela não pode ser elucidada a partir da Antropologia, por uma espécie de "análise da existência" (Daseinsanalyse). A necessidade da alienação da liberdade egoísta em nome da espécie (dever moral) se inscreve necessariamente em um pensamento metafísico.

O sentido do termo "uso" (Gebrauch), traduzido por Foucault como usage, marca justamente o conflito entre liberdade e natureza, anunciando o sentido histórico da visada pragmática em sua referência à necessidade metafísica. Ao que parece, em Kant, seu sentido histórico, e por isso conflituoso, está na "negociação" entre o egoísmo natural (liberdade selvagem) e a moral universalizante (liberdade moral naturalmente engendrada pela espécie). "De um ponto de vista metafísico, qualquer que seja o conceito que se faça da liberdade da vontade, as suas manifestações (Ersheinungen) - as ações humanas -, como todo outro acontecimento natural, são determinadas por leis naturais universais ${ }^{\prime \prime 4}$.

Assim, assegura Foucault, "é do sentido inicial da Antropologia ser Erforschung: exploração de um conjunto jamais ofertado em totalidade, jamais em repouso sobre si próprio porque tomado em um movimento no qual natureza e liberdade são intricadas no Gebrauch,

44. IAK, p. 23.

45. DE I, Introduction, 1, p. 133.

46. KANT, I. Ideia de uma bistória universal de um ponto de vista cosmopolita, p. 3. 
do qual nossa palavra uso (usage) cobre alguns dos sentidos" ${ }^{\prime \prime 7}$. A noção de uso (l'usage; Gebrauch) tem para Foucault o sentido de práxis, pois remete a certa indeterminação, por um lado, e à determinação do ponto em que se limita a ação, por outro. $\mathrm{O}$ uso se estabelece em um duplo sistema: "de obrigação firmada em relação a si, de distância respeitada em relação aos outros. Ele se localiza no texto de uma liberdade que se postula a um só tempo singular e universal"48. O uso fornece o sentido prático da experiência e o valor moral da ação.

"É então num bom uso da liberdade que se enraíza a possibilidade 'das menscbliche Leben zu verlängern' preservando a mecânica do corpo da queda culpável no mecanismo" ${ }^{\prime 49}$. Segundo a perspectiva de Hufeland, formulada nesses termos por Foucault, há um bom uso da liberdade a regular a vida empírica de acordo com o interesse da Razão, ou propósito da natureza. Nesse sentido, Foucault entende que a perspectiva de Hufeland sugere que o homem caracterizado pela liberdade selvagem, ao menos originariamente, é prático conforme regula o conflito (uso) entre essa liberdade e a natureza social (liberdade de outrem), e moral conforme esse uso se estabelece face à postulação da lei moral que tem em vista a espécie na história. Neste caso, trata-se efetivamente do cidadão do mundo, conforme o sujeito representa para si o valor - regulador - de uma universalidade que deve se impor à "pura liberdade". Sabe-se que o homem cosmopolita, prático e moral, é propriamente o foco da Antropologia pragmática.

\section{V}

Com efeito, o recuo de princípio kantiano, em relação às ciências objetivas, marca a novidade da filosofia moderna, na qual, por isso, a fenomenologia se inscreve absolutamente. Lebrun ressalta esse ponto para explicitar um dos motivos que a mostra bem instalada em uma episteme que poderia ser dita "pós-kantiana". "Desse ponto de vista, as críticas que Husserl endereça a Kant importam menos que a posição prévia que ele adota e que lhe permite formulá-las ${ }^{\prime \prime 50}$. Ainda na leitura

47. IAK, p. 32.

48. Idem, ibidem.

49. Idem, p. 28.

50. LEBRUN, G. Note sur la phénoménologie dans Les mots et les choses. In : Michel Foucault Pbilosophe, Rencontre Internationale, Janvier 1988. Paris: Seuil, 1989, p. 43 . 
de Lebrun, há um segundo aspecto que evidencia, por meio da crítica de Foucault, o lugar da fenomenologia como expressão de sua época e não como a retomada de um antigo projeto filosófico. Lebrun nota que Foucault inclui Husserl nesse "pós-kantismo" em função de dois traços: "o cuidado de fundar ('de ancorar os direitos e os limites de uma lógica formal na reflexão de tipo transcendental') e aquele de desvendar ('de reencontrar indefinidamente o transcendental no empírico') $)^{\prime 51}$. Este segundo aspecto estrutura exclusivamente o programa de Binswanger, de modo que é desta emboscada analítica que Foucault procura fugir revendo a necessidade da tripartição kantiana, particularmente na tese complementar de 1961.

\section{Referências}

FOUCAULT, M. Dits et écrits (1954-1988), 2 volumes. Paris: Gallimard, 2001. Introduction à l'Antbropologie de Kant. Thèse complémentaire pour le doctorat ès Lettres. Paris: VRIN, 2008.

Qu'est-ce que la Critique? [critique et Aufklärung]. In: Bulletin de la Société Française de Philosophie, séance du 27 Mai 1978, 84 année, n. 2, avril-juin, 1990.

HEIDEGGER, M. Meu caminho para a fenomenologia. Coleção Os pensadores. São Paulo: Abril Cultural, 1979.

KANT, I. Antbropologie du point de vue pragmatique. Traduit et prefacé par Michel Foucault. Paris: VRIN, 2002.

KANT, I. Ideia de uma bistória universal de um ponto de vista cosmopolita. São Paulo: Martins Fontes, 2004.

LEBRUN, G. Kant e o fim da metafísica (1970). Tradução de Carlos Alberto Ribeiro de Moura. São Paulo: Martins Fontes, 1993.

LEBRUN, G. Note sur la Phénoménologie dans Les Mots et les Choses. In: Michel Foucault Philosophe, Rencontre Internationale, Janvier 1988. Paris: Seuil, 1989.

PRIMO LEVI. É isto um bomem? Tradução de Luigi Del Re. Rio de Janeiro: Rocco, 1988.

51. Idem, ibidem. 